\title{
Interface Optimization and Mechanical Properties of Cu-coated Carbon Fiber Cloth/Titanium Alloy Composite
}

\author{
Yang Zhiming ${ }^{1}, \quad$ Wu Tengteng ${ }^{2}, \quad$ Liu Jinxu', $\quad$ Zhou Lin $^{3}, \quad$ Li Shukui ${ }^{1,4}$ \\ ${ }^{1}$ School of Materials Science and Engineering, Beijing Institute of Technology, Beijing 100081, China; ${ }^{2}$ Body Engineering Department, BAIC \\ Motor Corporation Ltd, Beijing 101300, China; ${ }^{3}$ Beijing Research Institute of Mechanical \& Electrical Technology, Beijing 100083, China; \\ ${ }^{4}$ State Key Laboratory of Explosion Science and Technology, Beijing Institute of Technology, Beijing 100081, China
}

\begin{abstract}
Using Cu-coated carbon fiber cloth (CFC) as reinforcement and Ti-6Al-4V (TC4) as matrix, the $\mathrm{Cu}-\mathrm{coated} \mathrm{CFC} / \mathrm{TC} 4$ composite was fabricated by spark plasma sintering. The interface morphology, phase microstructure, phase distribution and mechanical properties of CFC/TC4 were characterized. Results show that carbon fibers are uniformly distributed in $\mathrm{Cu}$-coated $\mathrm{CFC} / \mathrm{TC} 4$. $\mathrm{CuTi}, \mathrm{Cu}$ and trace $\mathrm{TiC}$ are distributed along the interface between fibers and matrix. The $\mathrm{Cu}-\mathrm{coated} \mathrm{CFC} / \mathrm{TC} 4$ possesses slightly better plasticity than TC4, and the yield strength and compressive strength are obviously enhanced. The electroplated $\mathrm{Cu}$ plays important roles: (1) markedly decreasing the sintering temperature of $\mathrm{Cu}$-coated CFC/TC4; (2) significantly improving the wettability and interfacial bonding between carbon fibers and TC4 matrix, thus increasing mechanical properties of $\mathrm{Cu}$-coated CFC/TC4; (3) effectively inhibits the excessiving generation of brittle TiC compared with uncoated CFC/TC4 composite, thus maintaining good plasticity of $\mathrm{Cu}$-coated CFC/TC4.
\end{abstract}

Key words: metal-matrix composites (MMCS); interface; sintering; mechanical properties; microstructure

Carbon fiber reinforced materials have been widely developed in metal matrix composites (MMCs) in the last decades, since they can endow MMCs good performance of thermostability, wear resistance and fatigue resistance ${ }^{[1-7]}$. Recent research has shown that continuous carbon fiber possesses its unique advantages compared with short carbon fiber. Advanced continuous fibers have produced a revolution in the field of structural materials and composites in the last few decades because of their high specific strength, specific modulus, stiffness, and continuity, which meant processing and alignment are economically feasible ${ }^{[8]}$. Daoud reported that the incorporation of continuous carbon fibers into $2014 \mathrm{Al}$ alloy significantly improved the wear resistance and the composite exhibited a higher seizure resistance compared with the unreinforced alloy ${ }^{[9]}$.

Continuous carbon fiber reinforced composites have aroused lots of attentions ${ }^{[10-13]}$, but most of them are about resin matrix and based on wear performance ${ }^{[9,14-17]}$. In recent years, research on continuous carbon fiber reinforced MMCs is relatively less mainly due to the following difficulties in the process of preparing composites ${ }^{[18-27]}$ : (1) Carbon fibers are difficult to be wetted by molten metals, and thus the interfacial bonding between fibers and matrix is weak; (2) Carbon fibers tend to react with metal matrix at high temperature to produce excessive brittle intermetallic compounds in the interface, making the interface a weak link; (3) Carbon fibers are easily oxidized, largely decreasing mechanical properties. In order to solve above problems, and to give full play to the unique advantages of long carbon fiber and to obtain long carbon fiber reinforced MMCs with much more excellent mechanical properties, a large amount of work concerning interfacial optimization have been carried out.

In terms of interface optimization, excessive interfacial 
reaction leads to the vast generation of brittle intermetallic compounds in the interface between fibers and metal matrix while non-reaction results in bad interfacial bonding. Therefore, the design parameters of interphases depend on the reactivity between the matrix and the reinforcements ${ }^{[28]}$. It is reasonable to reduce the interfacial reactions for highly reactive systems by coating ${ }^{[9,19,27,29,30]}$ and modify the surface chemistry of the reinforcement or change the matrix chemistry for non-reactive systems ${ }^{[28,31,32]}$ in order to achieve the desired interfacial bonding properties.

In recent years, carbon fiber reinforced titanium composites were reported to improve the mechanical properties of titanium ${ }^{[3,33-35]}$. But these reports were mostly on carbon nanotubes or short (chopped) carbon fibers in order to improve the wear resistance or static strength, and the preparation methods were normally casting and powder metallurgy. At present, there are few studies about controlling the generation of intermetallic compounds, and the problem of wettability between carbon fibers and titanium also has not been fundamentally solved. If the interfacial problems like poor wettability and serious carbonization of matrix can be solved in long carbon fiber reinforced titanium alloy, continuous carbon fibers would fully play the advantages of high elastic modulus, high tensile strength, high shear strength and low density to further enhance the mechanical properties of titanium alloy, which is an important development trend for lightweight structural material in the future.

In the present paper, aiming to control the carbonization degree of Ti-6Al-4V (TC4) at high temperature and to improve the wettability between carbon fibers and TC4 matrix, carbon fiber cloth (CFC) was coated with $\mathrm{Cu}$ by electroplating. Considering the lower sintering temperature, shorter sintering time and moderate uniaxial pressure ${ }^{[36-39]}$ of spark plasma sintering (SPS), we chose SPS to prepare CFC/TC4 composites. The static and dynamic mechanical properties of $\mathrm{CFC} / \mathrm{TC} 4$ composites were investigated.

\section{Experiment}

PAN-based CFC (T300) was selected as raw material. Each bundle consists of 1200 single filaments with a diameter of $6 \mu \mathrm{m}$. Thousands of single filaments cohere together and compose CFC by the adhesive force of binder. The glue membrane and some other grease infectants on the surface of carbon fibers are both bad for electroplating. In order to obtain uniform coating on individual fiber, CFC must be modified to improve the interfacial bonding between fibers and coating ${ }^{[40]}$. In this paper, the surface treatment of CFC before electroplating included two steps. The first step was carried out by thermal debinding at $400^{\circ} \mathrm{C}$ for $30 \mathrm{~min}$ in muffle furnace to burn out the organic binder on the surface of fibers. In the following step, the CFC was immerged in a $50 \%$ aqueous solution of nitric acid for $12 \mathrm{~h}$ to improve surface activity of fibers. After acid etching treatment, the CFC was cleaned for several times using deionized water.

After the pretreatments above, $\mathrm{Cu}$ was electroplated on the CFC to inhibit the carbonization of TC4 matrix and to improve the wettability between fibers and matrix. A plating aqueous solution with content of $150 \mathrm{~g} / \mathrm{L} \mathrm{CuSO}_{4}$ and $50 \mathrm{~g} / \mathrm{L} \mathrm{H}_{2} \mathrm{SO}_{4}$ was applied to electroplate $\mathrm{Cu}$ on the surface of CFC. The CFC acting as cathode was placed between two $\mathrm{Cu}$ anode plates in the bath, and then pulse current with duty cycle of $80 \%$ was imposed on $\mathrm{Cu}$ and $\mathrm{CFC}$ for $2 \mathrm{~h}$. The current density was $3 \mathrm{~A} / \mathrm{dm}^{2}$ and the electroplating temperature was $24^{\circ} \mathrm{C}$. After that, the $\mathrm{Cu}$-coated $\mathrm{CFC}$ was washed in distilled water for several times and lastly dried in a vacuum drying oven at $100^{\circ} \mathrm{C}$. Images of $\mathrm{CFC}$ before and after electroplating of $\mathrm{Cu}$ are shown in Fig. 1.

TC4 was selected to be the matrix and $\mathrm{Cu}$-coated $\mathrm{CFC} / \mathrm{TC} 4$ composite was prepared by SPS. For comparison, uncoated CFC/TC4 composite was also fabricated. The images of uncoated and $\mathrm{Cu}$-coated $\mathrm{CFC}$ and original TC4 material are shown in Fig. 2. With a diameter of $40 \mathrm{~mm}$, CFC and TC4 sheets were put into a cylindrical graphite die with an inner diameter of $40 \mathrm{~mm}$. Fig.3 shows the schematic of the procedure to fabricate $\mathrm{CFC} / \mathrm{TC} 4$ composites. In order to prevent TC4 sheets from reacting with the graphite die or punches, graphite foil was used. After several times of process optimization, the specimens were subjected to SPS using the following parameters: (1) heated from room temperature to $1050{ }^{\circ} \mathrm{C}$ (for $\mathrm{Cu}$-coated CFC/TC4 composite) or $1500{ }^{\circ} \mathrm{C}$ (for uncoated CFC/TC4 composite) with a heating rate of $100{ }^{\circ} \mathrm{C} / \mathrm{min}$; (2) pressed by a uniaxial pressure of $50 \mathrm{MPa}$; (3) held at $1050{ }^{\circ} \mathrm{C}$ (for $\mathrm{Cu}$-coated $\mathrm{CFC} / \mathrm{TC} 4$ composite) or $1500{ }^{\circ} \mathrm{C}$ (for uncoated $\mathrm{CFC} / \mathrm{TC} 4$ composite) for $15 \mathrm{~min}$. The obtained $\mathrm{Cu}$-coated CFC/TC4 composite is shown in Fig.4.

Microscopic images, elemental composition and phase distribution of composites were obtained by field emission scanning electron microscopy (FESEM, S-4800), energy dispersive spectroscopy (EDS, FEI Tecnai G2F20) and transmission electron microscopy (TEM, JEM-2100). Phase identification was carried out using an X-ray diffraction (XRD, D8 ADVANCE).
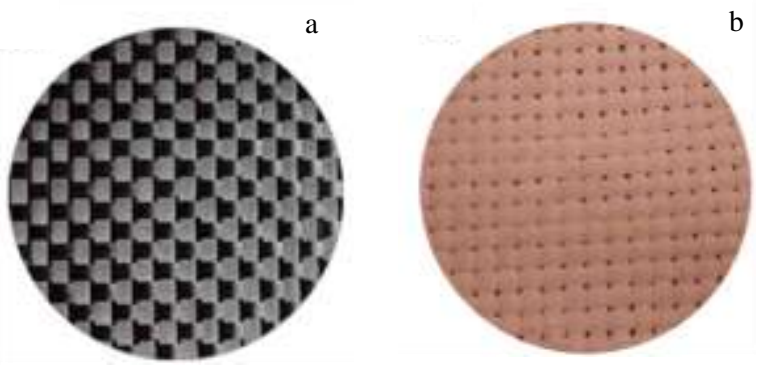

Fig.1 Images of CFC before (a) and after (b) electroplating of $\mathrm{Cu}$ 

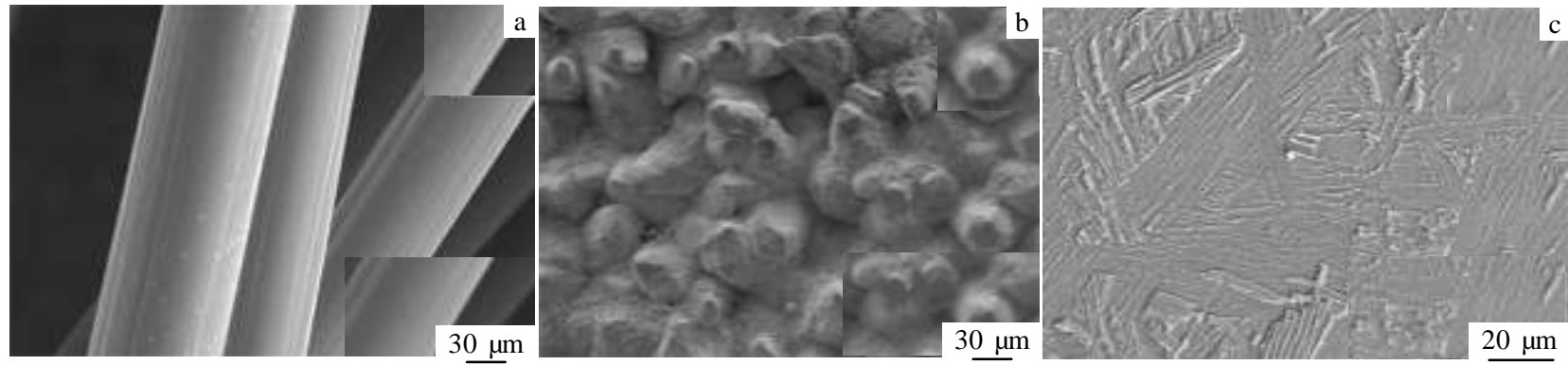

Fig.2 FESEM images of raw material for composites: (a) uncoated CFC, (b) Cu-coated CFC, and (c) original TC4
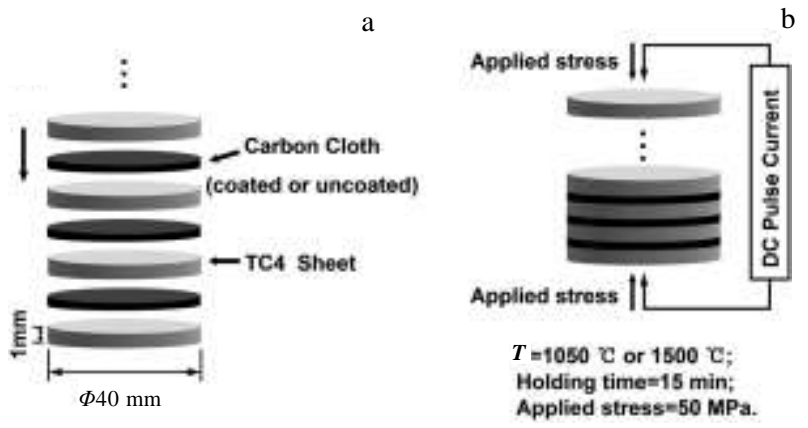

Fig.3 Schematic of the procedure to fabricate CFC/TC4 composites: (a) the assembly sequence of composites and (b) preparation of composites by SPS

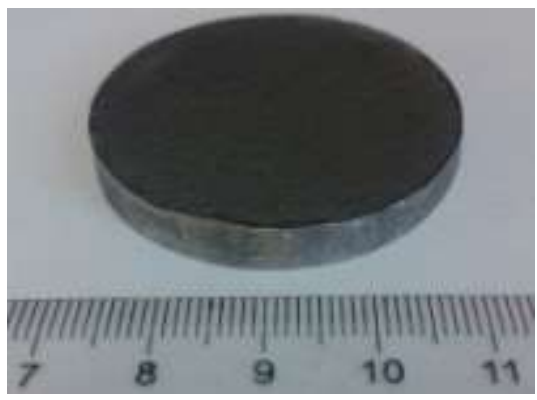

Fig.4 Macroscopic image of $\mathrm{Cu}$-coated CFC/TC4 composite

The quasi-static (at a strain rate of $10^{-3} \mathrm{~s}^{-1}$ ) and dynamic (at a strain rate of $4200 \mathrm{~s}^{-1}$ ) compression tests were used to characterize the mechanical properties of the samples. Quasi-static compressive experiments were conducted at a computer controlled electronic universal test machine, and the dynamic compressive experiments were performed on split Hopkinson bars (SHPB) facility. The bars of SHPB facility were made of maraging steel with Young's modulus of $197 \mathrm{GPa}$, density of $7.8 \mathrm{~g} / \mathrm{cm}^{3}$ and wave speed of 4998 $\mathrm{m} / \mathrm{s}$. The diameter of the striker bar, incident bar and transmission bar was $14.5 \mathrm{~mm}$, and their length were 200 , 800 and $800 \mathrm{~mm}$, respectively. The duration of the pulse was $80 \mu \mathrm{s}$. The cylindrical specimen (with a diameter of 5 $\mathrm{mm}$ and a thickness of $4 \mathrm{~mm}$ ) was sandwiched between the incident bar and the transmission bar.

\section{Results and Discussion}

\subsection{Microstructure characterization}

Fig.5a and Fig.5d show the polished section surface morphologies of $\mathrm{Cu}$-coated $\mathrm{CFC} / \mathrm{TC} 4$ composite and uncoated CFC/TC4 composite. Fig.5b, Fig.5c, Fig.5e and Fig.5f are magnification of region $\mathrm{A}$ in Fig.5a, region $\mathrm{B}$ in Fig.5b, region $\mathrm{D}$ in Fig.5d and region $\mathrm{E}$ in Fig.5e, respectively. From Fig.5a and Fig.5d, it can be observed that, at macro level, $\mathrm{Cu}$-coated $\mathrm{CFC} / \mathrm{TC} 4$ composite possesses a better interfacial bonding compared with uncoated CFC/TC4 composite. There is hardly any TC4 infiltrating into the interspaces among carbon fibers in uncoated CFC/TC4 composite (Fig.5e and Fig.5f), which indicates the poor wettability between carbon fibers and TC4 matrix. But in Cu-coated CFC/TC4 composite, TC4 infiltrates well into the interspaces among carbon fibers without discernible debonding, pore or micro-crack (Fig.5b and Fig.5c). As carbon fibers in CFC have two perpendicular directions in warp and weft, and the cutting direction is neither parallel nor perpendicular to the length direction of carbon fiber, there exists elliptic morphology of carbon fibers in Fig.5b. The comparison above indicates that $\mathrm{Cu}$-coating could significantly improve the wettability between carbon fibers and TC4 matrix, and evidently decrease the sintering temperature of $\mathrm{Cu}$-coated $\mathrm{CFC} / \mathrm{TC} 4$ composite from 1500 to $1050{ }^{\circ} \mathrm{C}$.

Fig.6 shows the XRD patterns taken from $\mathrm{Cu}$-coated CFC/TC4 composite (Fig.6a) and uncoated CFC/TC4 composite (Fig.6b). According to the XRD patterns, new phases generated in $\mathrm{Cu}$-coated $\mathrm{CFC} / \mathrm{TC} 4$ composite are $\mathrm{TiC}$ and $\mathrm{CuTi}$, while $\mathrm{TiC}$ is the only new phase in uncoated CFC/TC4 composite.

Though it is hard for TC4 to infiltrate into the interspaces among the carbon fibers, combined with FESEM-EDS (not listed here) and XRD result, an analysis finds that there are a large number of carbon atoms diffusing into TC4 matrix, generating a large amount of TiC. Fig. 7a and Fig.7b are the locally magnified images of Fig.5d and Fig.7a, respectively, showing the distribution and morphology of generated TiC 

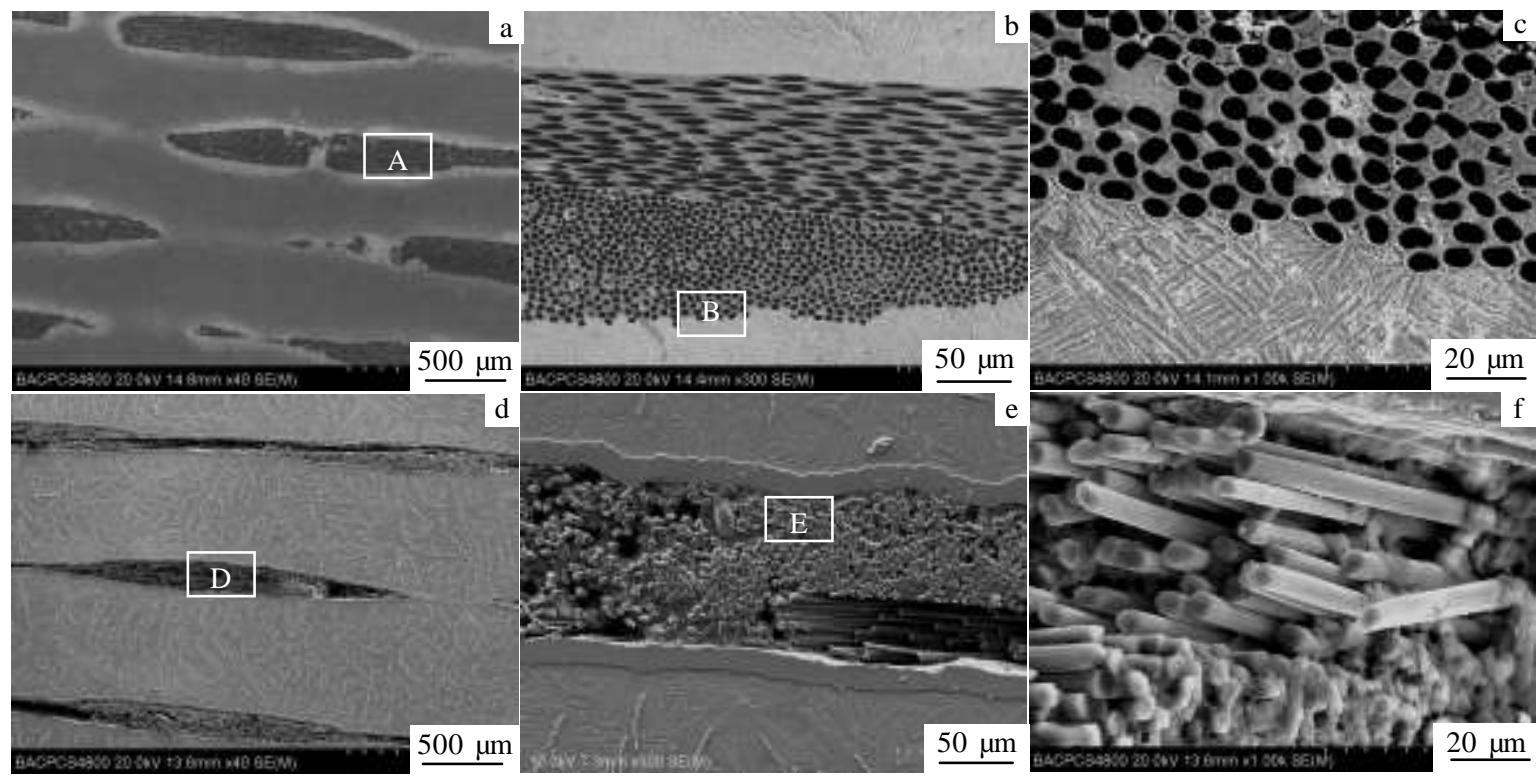

Fig.5 FESEM images of $\mathrm{Cu}$-coated CFC/TC4 composite: (a) low magnification, (b) magnification of region A in Fig.5a, and (c) magnification of region B in Fig.5b; FESEM images of uncoated CFC/TC4 composite: (d) low magnification, (e) magnification of region D in Fig.5d, and (f) magnification of region E in Fig.5e
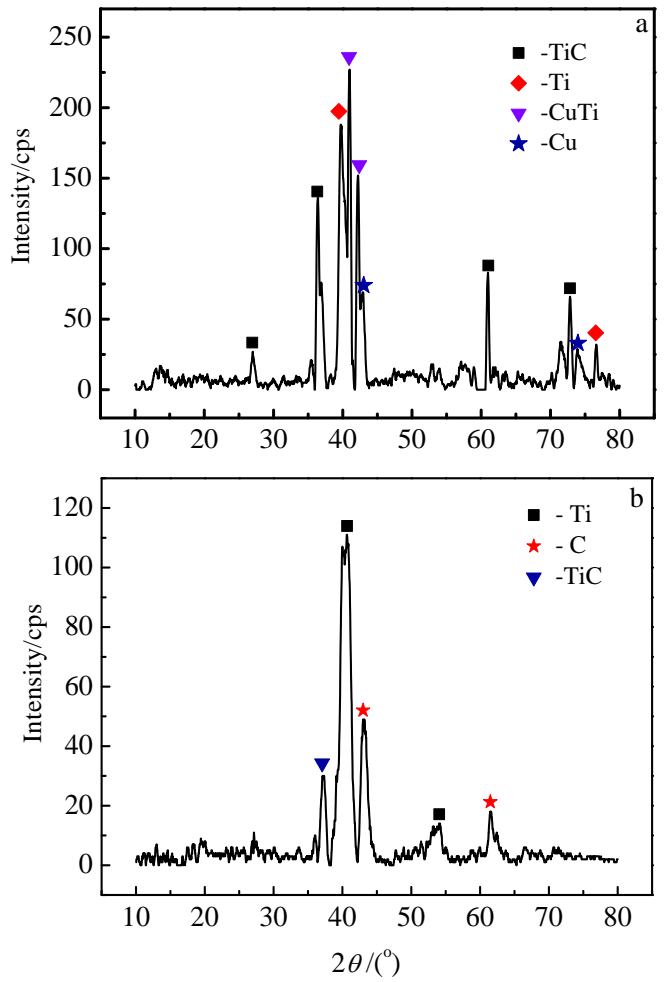

Fig.6 XRD patterns of $\mathrm{Cu}$-coated $\mathrm{CFC} / \mathrm{TC} 4$ composite (a) and uncoated $\mathrm{CFC} / \mathrm{TC} 4$ composite (b)

in uncoated CFC/TC4 composite. Fig.7 shows that lamellar TiC exists throughout the TC4 matrix in uncoated CFC/TC4 composite, while Fig.5a and FESEM-EDS (not listed here) show that there is no carbon element detected within TC4 matrix in $\mathrm{Cu}$-coated $\mathrm{CFC} / \mathrm{TC} 4$ composite, indicating that there is no $\mathrm{TiC}$ generated in $\mathrm{TC} 4$ matrix. It confirms that $\mathrm{Cu}$-coating could inhibit the generation of TiC effectively by cutting off the diffusion path of carbon atoms.

Fig. 8 shows the TEM images of interfacial microstructure and phase distribution in $\mathrm{Cu}$-coated $\mathrm{CFC} / \mathrm{TC} 4$ composite. Fig. 8b, Fig.8c and Fig.8e are magnification of region $\mathrm{C}$, region $\mathrm{A}$ and region $\mathrm{B}$ marked in Fig.8a, respectively. Selected area diffraction patterns shown in Fig. 8d and Fig. 8f were taken from Fig.8c and Fig.8e, respectively. It can be seen from Fig. 8 a that the surface of carbon fiber is coated with two thin and uniform interfacial layers $\mathrm{C}$ and $\mathrm{B}$ from inside to outside. According to Fig. $8 \mathrm{~b}$ and Fig.8e, we get to know they are $\mathrm{CuTi}$ layer (about $60 \mathrm{~nm}$ ) and $\mathrm{Cu}$ layer (about 500nm), respectively. Between TC4 matrix and $\mathrm{Cu}$ layer, there exists a small amount of TiC particles. Fig. 9a shows macroscopic distribution of $\mathrm{Cu}$-coated $\mathrm{CFC} / \mathrm{TC} 4$ composite and Fig.9b shows macroscopic distribution of phases in reaction region. Compared with Fig.7, the $\mathrm{Cu}$-coating is evidently proved to play a positive role in inhibiting the formation of $\mathrm{TiC}$. There are several mechanisms for the fiber-matrix bonding, involving mechanical interlocking, chemical interaction, adsorption interaction and hydrogen bond interaction ${ }^{[41-44]}$. Generally these mechanisms influence the interfacial adhesion of composites simultaneously ${ }^{[45]}$.

Obviously, chemical interaction and mechanical interlocking mechanisms play dominating roles in this $\mathrm{Cu}$ coated CFC/TC4 composite. Thermal debinding and acid etching pretreatments are effective methods to create mechanical interlocking at fiber/matrix interface, and $\mathrm{Cu}$ - 


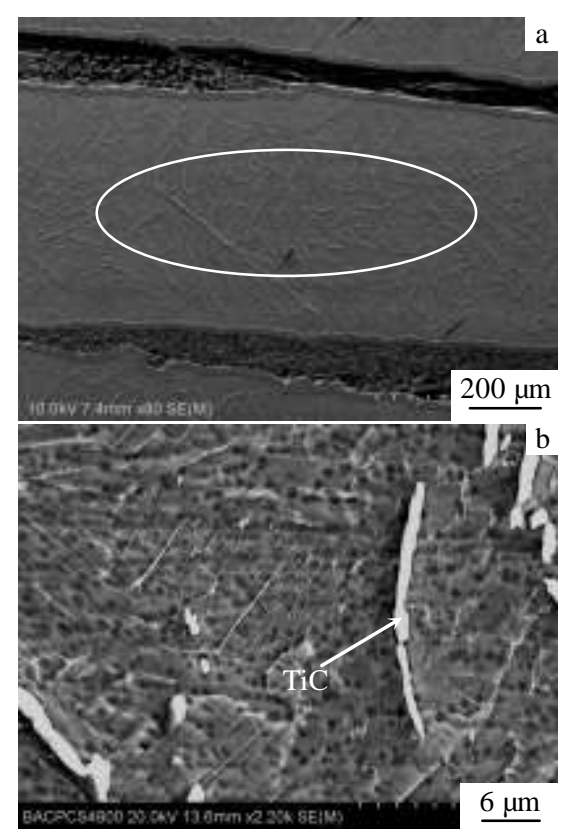

Fig.7 FESEM images of generated $\mathrm{TiC}$ in uncoated $\mathrm{CFC} / \mathrm{TC} 4$ composite: (a) macroscopic and (b) microscopic

coating is beneficial to enhance the interfacial adhesion by reacting with titanium during SPS. As previously mentioned, overreaction and non-reaction are both not optimal, and what we want is to control the content of $\mathrm{CuTi}$ and $\mathrm{TiC}$, namely to make it moderate, which is advantageous to interfacial bonding and does not cause brittleness. According to the comparison and analysis above, $\mathrm{Cu}$-coating is proved to realize this purpose perfectly: on the one hand, the interfacial bonding between carbon fibers and TC4 matrix is found to be improved significantly, which is benefited from the modest generation of CuTi and TiC compounds; on the other hand, the reaction between carbon fibers and TC4 matrix is effectively inhibited without excessive generation of brittle $\mathrm{TiC}$, owing to the $\mathrm{Cu}$ barrier. What's more, by adjusting the thickness of $\mathrm{Cu}$ layer, the degree of reaction between carbon fibers and matrix, namely the amount of TiC, can also be adjusted.

\subsection{Mechanical property tests}

The quasi-static and dynamic compressive stress-strain curves of original TC4 and $\mathrm{Cu}$-coated $\mathrm{CFC} / \mathrm{TC} 4$ composite are presented in Fig.10a and Fig.10b, respectively. $\mathrm{Cu}$-coated CFC/TC4 composite possesses slightly better plasticity than original TC4, and its the yield strength and ultimate compressive strength of are enhanced by the addition of CFC evidently. At a strain rate of $10^{-3} \mathrm{~s}^{-1}$, the yield and ultimate compressive strength of $\mathrm{Cu}$-coated CFC/TC4 composite increase by 230 and $100 \mathrm{MPa}$ compared with that of TC4, respectively. Additionally, at a strain rate of $4200 \mathrm{~s}^{-1}$, they increase by 370 and $220 \mathrm{MPa}$, respectively. The mechanical results above indicate that the addition of CFC is beneficial for TC4 being applied to situations requiring high static and dynamic strength. Moreover, the density of $\mathrm{Cu}$-coated $\mathrm{CFC} / \mathrm{TC} 4$ composite is dramatically decreased from 4.4 to $3.9 \mathrm{~g} / \mathrm{cm}^{3}$ compared with $\mathrm{TC} 4$, which indicates that the obtained $\mathrm{Cu}$-coated $\mathrm{CFC} / \mathrm{TC} 4$ composite can be used as lightweight structural material. It is important to mention that CFC still couldn't fully play its unique advantages due to the relatively small tested samples. The mechanical properties of $\mathrm{Cu}$-coated $\mathrm{CFC} / \mathrm{TC} 4$ composite will be further improved if we enlarge the volume of sample and further reduce the thickness of TC4 sheets.

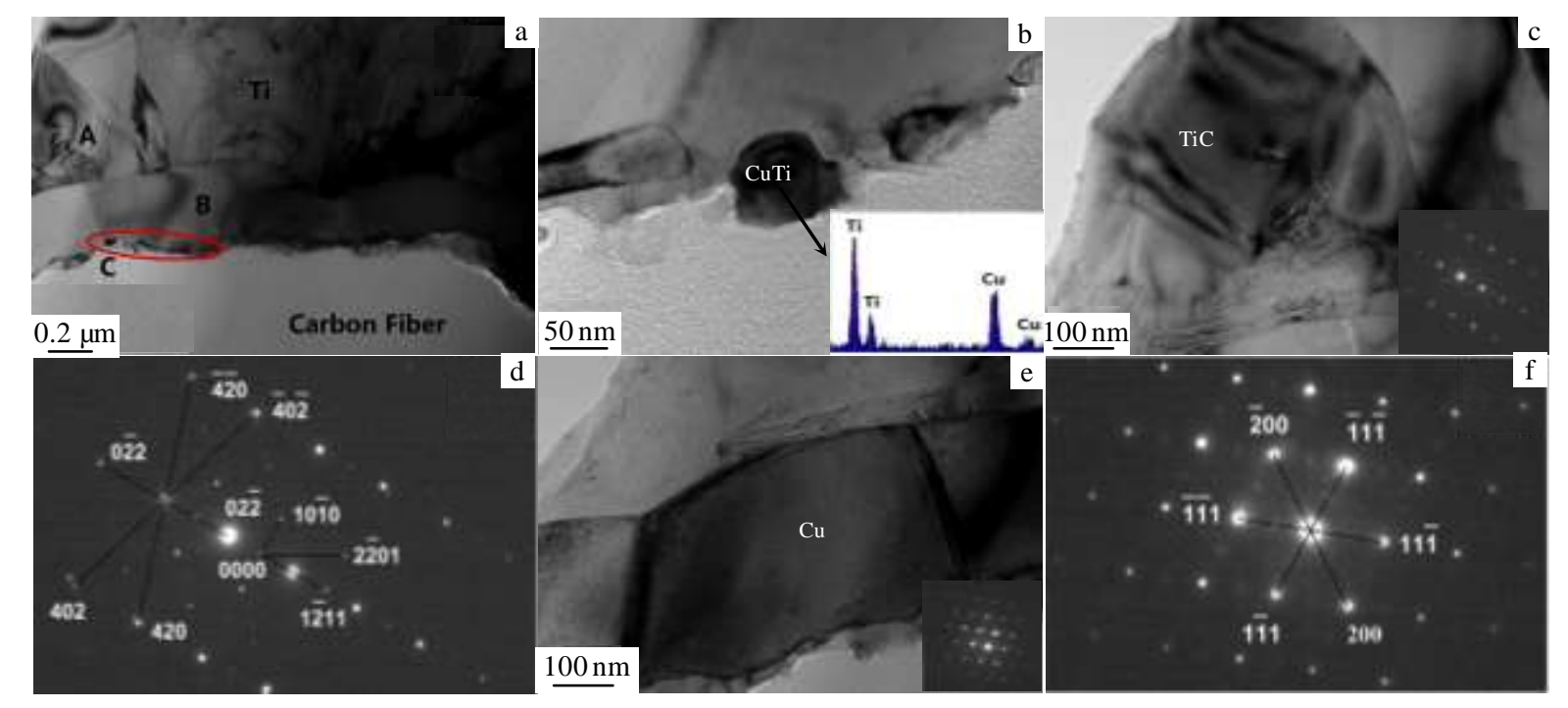

Fig.8 TEM images of Cu-coated CFC/TC4 composite: (a) voverall microstructure of interface; (b) morphology of CuTi and its EDS result (in the lower right of Fig.8b); (c) morphology of TiC; (d) selected area diffraction pattern of Fig.8c; (e) morphology of Cu and (f) selected area diffraction pattern of Fig.8e 


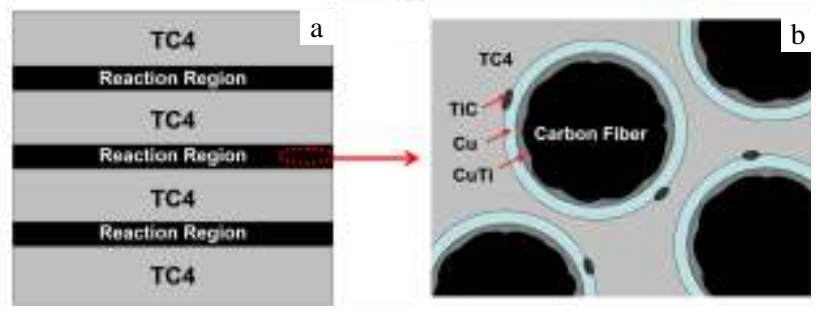

Fig.9 Schematic of the phase distribution in $\mathrm{Cu}$-coated $\mathrm{CFC} /$ TC4 composite: (a) macroscopic distribution of $\mathrm{Cu}$-coated $\mathrm{CFC} / \mathrm{TC} 4$ composite and (b) macroscopic distribution of phases in reaction region
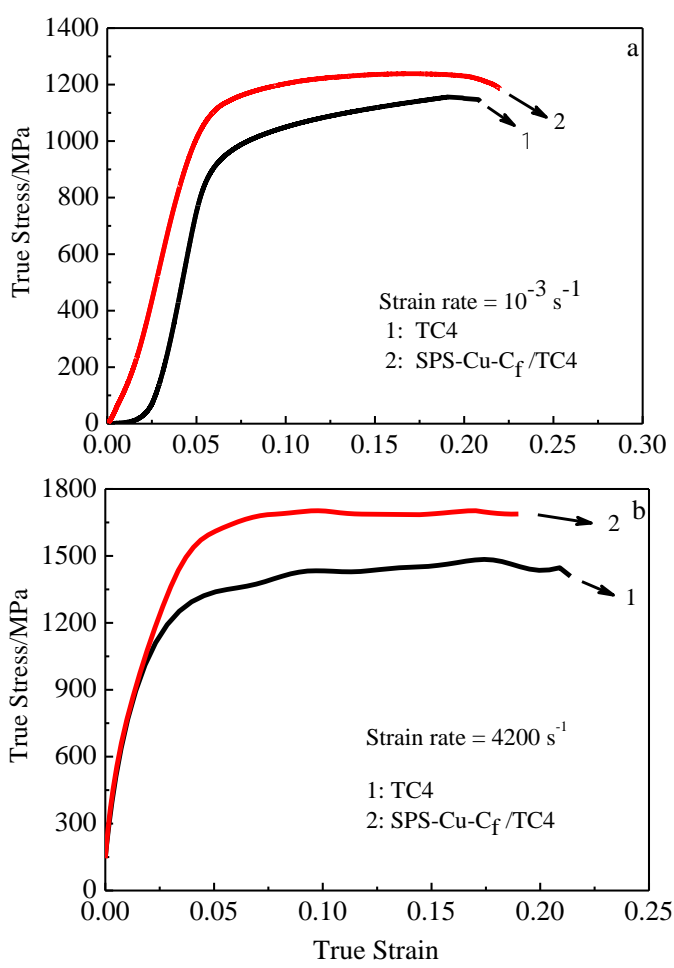

Fig.10 Compressive stress-strain curves at different strain rates: (a) $10^{-3} \mathrm{~s}^{-1}$ and (b) $4200 \mathrm{~s}^{-1}$

\section{Conclusions}

1) A novel kind of $\mathrm{Cu}$-coated $\mathrm{CFC} / \mathrm{TC} 4$ composite is fabricated by SPS. Carbon fibers are uniformly distributed in the $\mathrm{Cu}$-coated $\mathrm{CFC} / \mathrm{TC} 4$ composite with good interfacial bonding between carbon fibers and TC4 matrix. By the addition of $\mathrm{CFC}$, the yield strength and ultimate compressive strength of $\mathrm{Cu}$-coated $\mathrm{CFC} / \mathrm{TC} 4$ are significantly enhanced. At a strain rate of $10^{-3} \mathrm{~s}^{-1}$, they increase by 230 and $100 \mathrm{MPa}$, respectively; while at a strain rate of $4200 \mathrm{~s}^{-1}$, they increase by 370 and $220 \mathrm{MPa}$, respectively. Additionally, the $\mathrm{Cu}$-coated $\mathrm{CFC} / \mathrm{TC} 4$ composite still possesses well capacity of plastic deformation.
2) The roles of $\mathrm{Cu}$ in $\mathrm{Cu}$-coated $\mathrm{CFC} / \mathrm{TC} 4$ composite are as follows aspects: (1) markedly decreasing the sintering temperature of $\mathrm{Cu}$-coated $\mathrm{CFC} / \mathrm{TC} 4$ composite from $1500{ }^{\circ} \mathrm{C}$ to $1050{ }^{\circ} \mathrm{C}$ with better interfacial properties; (2) significantly improving the wettability and interfacial bonding, which is benefited from the modest generation of $\mathrm{CuTi}$ and $\mathrm{TiC}$ compounds and gives explanation to the increase of mechanical properties of $\mathrm{Cu}$-coated CFC/TC4.

3) Effectively inhibiting the excessive generation of brittle TiC compared with uncoated CFC/TC4 composite, thus maintaining good plasticity of $\mathrm{Cu}$-coated $\mathrm{CFC} / \mathrm{TC} 4$. By adjusting the thickness of $\mathrm{Cu}$ layer, the amount of $\mathrm{TiC}$ can also be adjusted.

Acknowledgements: China National Key Laboratory of Science and Technology on Materials under Shock and Impact is acknowledged

\section{References}

1 Koziol K, Vilatela J, Moisala A et al. Science[J], 2007, 318(5858): 1892

2 Roy A K, Schulze S, Hietschold M et al. Carbon[J], 2012, 50(3): 761

3 Kuzumaki T, Ujiie O, Ichinose $\mathrm{H}$ et al. Advanced Engineering Materials[J], 2000, 2(7): 416

4 Baughman R H, Zakhidov A A, de Heer W A. Science[J], 2002, 297(5528): 787

5 Treacy M M J, Ebbesen T W, Gibson J M. Nature[J], 1996 , 381(20): 678

6 Feldhoff A, Pippel E, Woltersdorf J. Advanced Engineering Matrials[J], 2000, 2(8): 471

7 Yu M F, Lourie O, Dyer M J et al. Science[J], 2000, 287(5453): 637

8 Dzenis Y. Science[J], 2004, 304(5679): 1917

9 Daoud A. Materials Letters[J], 2004, 58(25): 3206

10 Jochum C h, Grandidier J C, Smaali M A. Composites Science and Technology[J], 2007, 67(11): 2633

11 Li T Q, Zhang M Q, Zhang K et al. Polymer[J], 2000, 41(1): 161

12 Akay M, Spratt G R, Meenan B. Composites Science and Technology[J], 2003, 63(7): 1053

13 Liu X, Ji W, Zhang Y et al. Carbon[J], 2008, 46(1): 154

14 Sharma M, Rao I M, Bijwe J. Wear[J], 2009, 267(5): 839

15 Rahman M, Ramakrishna S, Prakash J R S et al. Journal of Materials Processing Technology[J], 1999, 89: 292

16 Zhang X R, Pei X Q, Zhang J P et al. Colloids and Surfaces $A[\mathrm{~J}], 2009,339(1): 7$

17 Sharma M, Rao M, Bijwe J. Tribology International[J], 2010, 43(5): 959

18 Matsunaga T, Matsuda K, Hatayama T et al. Composites Part $A[\mathrm{~J}], 2007,38(8): 1902$

19 Daoud A. Materials Science and Engineering $A[\mathrm{~J}], 2005$, 391(1): 114

20 Hajjari E, Divandari M, Mirhabibi A R. Materials and 
Design[J], 2010, 31(5): 2381

21 Liu Z G, Mang X B, Chai L H et al. Journal of Alloys and Compounds[J], 2010, 504: S512

22 Khoddamzadeh A, Liu R, Liang M et al. Composites Part A[J], 2012, 43(3): 344

23 Deng C F, Zhang X X, Wang D Z. Mater Letter[J], 2007, 61(3): 904

24 Etter T, Papakyriacou M, Schulz P et al. Carbon[J], 2003, 41(5): 1017

25 Gawad O A, Abou Tabl M H, Abdel Hamid Z et al. Surface and Coatings Technology[J], 2006, 201(3): 1357

26 So K P, Jeong J C, Park J G et al. Composites Science and Technology[J], 2013, 74: 6

27 Tang Y P, Liu L, Li W W et al. Applied Surface Science[J], 2009, 255(8): 4393

28 Veillère A, Sundaramurthy A, Heintz J M et al. Acta Materialia[J], 2011, 59(4): 1445

29 Bhav Singh B, Balasubramanian M. Journal of Materials Processing Technology[J], 2009, 209(4): 2104

30 Tang Y P, Deng Y D, Zhang K et al. Ceramics International[J], 2008, 34(7): 1787

31 Casalegno V, Salvo M, Ferraris M. Carbon[J], 2012, 50(6): 2296

32 Wang W G, Xiao B L, Ma Z Y. Composites Science and Technology[J], 2012, 72(2): 152

33 Melendez I M, Neubauer E, Angerer $\mathrm{P}$ et al. Composites
Science and Technology[J], 2011, 71(8): 1154

34 Even C, Arvieu C, Quenisset J M. Composites Science and Technology[J], 2008, 68(6):1273

35 Kondoh K, Threrujirapapong $\mathrm{T}$, Imai $\mathrm{H}$ et al. Composites Science and Technology[J], 2009, 69(7): 1077

36 Hulbert D M, Jiang D T, Dudina D V et al. International Journal of Refractory Metals and Hard Materials[J], 2009, 27(2): 367

37 Feng H B, Meng Q C, Zhou Y et al. Materials Science and Engineering $A[\mathrm{~J}], 2005,397(1): 92$

38 Anselmi-Tamburini U, Gennari S, Garay J E et al. Materials Science and Engineering A[J], 2005, 394(1): 139

39 Hulbert D M, Jiang D T, Anselmi-Tamburini U et al. Materials Science and Engineering A[J], 2008, 493(1): 251

40 Hua Z S, Liu Y H, Yao G C et al. Journal of Materials Engineering and Performance[J], 2012, 21(3): 324

41 Zhang H, Zhang Z, Breidt C. Composites Science and Technology[J], 2004, 64(13): 2021

42 Kalantar J, Drzal L T. Journal of Materials Science[J], 1990, 25(10): 4186

43 Guo J H, Lu C X, An F et al. Materials Letters[J], 2012, 66(1): 382

44 Zhao F, Huang Y D. Materials Letters[J], 2010, 64(24): 2742

$45 \mathrm{Xu} \mathrm{Z} \mathrm{W}$, Chen L, Huang Y D et al. European Polymer Journal[J], 2008, 44(2): 494

\title{
钛合金/碳纤维布复合材料的界面与力学性能的研究
}

\author{
杨智明 ${ }^{1}$, 吴腾腾 ${ }^{2}$, 刘金旭 ${ }^{1}$, 周 林 $^{3}$, 李树奎 ${ }^{1,4}$ \\ (1. 北京理工大学 材料学院, 北京 100081) \\ (2. 北京汽车股份有限公司, 北京 101300) \\ (3. 北京机电研究所, 北京 100083)
}

(4. 北京理工大学 爆炸科学与技术国家重点实验室, 北京 100081)

\begin{abstract}
摘 要: 选用 Ti-6Al-4V (TC4)钛合金为基体，镀铜碳纤维布为增强相来制备钛合金/碳纤维布复合材料。通过放电等离子烧结法 (SPS) 对镀铜碳纤维布与钛合金薄片进行叠层烧结，制备钛合金/碳纤维布叠层复合材料，并对其界面形貌、微观组织与力学性能进行表征。 结果表明：镀铜碳纤维均匀分布在钛合金/碳纤维布复合材料中, $\mathrm{CuTi}, \mathrm{Cu}$ 和少量的 $\mathrm{TiC}$ 沿着纤维和基体的界面分布。钛合金/碳纤维 布复合材料具有比钛合金略高的塑性，同时屈服强度和抗压强度与钛合金相比有了明显的提高。碳纤维表面电镀铜对复合材料界面有 着重要的影响:（1）显着降低钛合金/碳纤维布复合材料的烧结温度;（2）提高了碳纤维和钛基体之间的润湿性，改善了界面结合，从 而提高了钛合金/碳纤维布复合材料的力学性能; (3) 有效地抑制 $\mathrm{TiC}$ 脆性相的产生，与未镀铜的碳纤布增强钛复合复合材料相比，镀 铜碳纤维布/钛合金复合材料具有更好的塑性。
\end{abstract}

关键词：金属基复合材料; 界面; 烧结; 力学性能; 微观组织

作者简介: 杨智明, 男, 1990 年生, 博士生, 北京理工大学材料学院, 北京 100081, 电话: 010-68913937, E-mail: ymzyangzhiming@ 163.com 